\title{
Whacking Bush: Tactical Media as Play
}

\section{Graham Meikle}

'The great archetypal activities of human society are all permeated with play from the start' (Johan Huizinga)

'Rarely is the question asked: is our children learning?' (George W. Bush)

\section{Introduction - Bushwhacked?}

In 2003, US President George W. Bush's State of the Union speech staked out some distinctive positions:

Mr Speaker, Vice-President Cheney, members of Congress, distinguished citizens and fellow citizens. Every year, by law and by custom, we meet here to threaten the world. The American flag stands for corporate scandals, recession, stock market declines, blackmail, terror, burning with hot irons, dripping acid on the skin, mutilation with electric drills, cutting out tongues, and rape. Our first goal is to show utter contempt for the environment... And this year, for the first time, we must offer every child in America three nuclear missiles... Secretary of State Powell will plant information to incite fear about Iraq's links to terrorist groups. And tonight I have a message for the people of Iraq - go home and die. Trusting in the sanity and restraint of the United States is not a strategy and it is not an option. 
Anyone reading a book about tactical media may well be familiar with the four-minute video from which this is extracted, 'Bushwhacked', which circulated widely online in $2004 .{ }^{1}$ Created by UK satirist Chris Morris, the 'Bushwhacked' video was assembled from footage of Bush's actual State of the Union speech, cut with audio samples from this and other speeches, and remixed to create an arresting new hybrid. This video, while an accomplished satirical intervention, was far from unique - in 2004 it looked at times as though more people were remixing Bush than were voting for him.

Scores of such mash-ups are posted on video-sharing website YouTube: Bush singing U2's 'Sunday Bloody Sunday'; Bush and UK Prime Minister Tony Blair duetting on Diana Ross and Lionel Richie's 'Endless Love', or Electric Six's 'Gay Bar', among others. In one of the most elaborate examples, Australian artist Wax Audio created 'Imagine This', a sophisticated mash-up of John Lennon's 'Imagine' and 'Give Peace A Chance', with a painstaking assemblage of authentic snatches of Bush speeches sequenced to have the president 'perform' the songs <http: / / www.waxaudio.com.au>. Moreover, some of these remixes and mash-ups were coordinated: in one example, the website of 'virtual band' The Bots organised a contest for remixes of Bush speeches set to original music, to be made using its George W. Bush Public Domain Audio Archive <http: / / www.thebots.net/GWBushSampleArchive.htm>. This archive offers mp3 and .wav files of Bush speeches, as well as named samples of individual phrases (such as 'freedom is beautiful' or 'go home and die') The complete archive runs to 15,000 samples: enough data to fill three DVDs. $^{2}$

Of course, Bush had generated such remix-interventions in his first presidential campaign too. For example, ${ }^{\circledR}{ }^{\mathrm{TM}}$ ark's $<$ gwbush.com $>$ 
website, which cloned and subverted Bush's official $<$ georgewbush.com> page, and provoked the Bush campaign into registering for themselves dozens of such addresses as $<$ bushblows.org $>$ and $<$ bushsucks.com $>$. The official Bush campaign set these up as aliases to the candidate's real site, thus blocking anyone else from registering them and joining the satirical fray (Meikle 2002: 117).

'Reality', James Carey once argued, 'is a scarce resource' - one which people compete to control (1989: 87). In the digital era, this competition remains fierce, but the raw material is no longer in such short supply. Defining reality, carving up and exploiting that resource, is one of the central phenomena of the media. As US President, Bush not only occupies the paramount position in US electoral politics, but he is also a symbol at the heart of a burgeoning activist participatory culture: one which manifests itself by, among other things, creating and circulating remixes, mash-ups, and subverted texts and imagery of all kinds. As US President, Bush exercises and is implicated in the political power of government, the coercive power of the military and the law, and the economic power of corporations - but he also exercises and is implicated in symbolic power: what John B. Thompson characterises as the capacity 'to intervene in the course of events, to influence the actions of others and indeed to create events, by means of the production and transmission of symbolic forms' (1995: 17). Thompson is here building upon the work of Bourdieu, who characterised symbolic power as 'a power of constituting the given through utterances, of making people see and believe [...] an almost magical power which enables one to obtain the equivalent of what is obtained through force' (Bourdieu 1991: 170). 
This chapter is concerned with particular expressions of symbolic power: those which can be usefully understood as tactical media. Tactical media practice trades in symbolic power - and increasingly this is not just the domain of quasi-professional groups

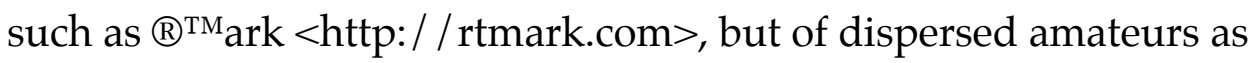
well. These are, of course, unequal power relations, which could perhaps be classed with what anthropologist James C. Scott identifies as 'the ordinary weapons of relatively powerless groups: foot dragging, dissimulation, false compliance, pilfering, feigned ignorance, slander, arson, sabotage, and so forth' (Scott 1985: 29). 'A tactic,' as Michel de Certeau put it, 'is an art of the weak' (1984: 37). However, while it would be a mistake to overstate or over-romanticise such tactics, such 'weapons of the weak', it would also be a mistake to dismiss them. This chapter first reviews some of the key definitions of the elusive discourse of tactical media, before developing an account of its key characteristics through the use of an extended example: the 'Revolution: USA' project. It goes on to argue that tactical media can be productively analysed through a number of concepts of play.

\section{Tactical Media?}

Tactical media mix creative subversion and subversive creativity. The 'manifesto' of the discourse, 'The ABC of Tactical Media' by David Garcia and Geert Lovink (1997), opens with the following definition:

Tactical Media are what happens when the cheap 'do it yourself' media, made possible by the revolution in consumer electronics and expanded forms of distribution (from public access cable to the internet) are exploited by groups and individuals who feel aggrieved by or excluded from the wider culture. 
Tactical media has been both theorised and practiced at the series of Next 5 Minutes (N5M) events held in The Netherlands. The third of these, in 1999, offered the following definition:

The term 'tactical media' refers to a critical usage and theorisation of media practices that draw on all forms of old and new, both lucid and sophisticated media for achieving a variety of specific non-commercial goals and pushing all kinds of potentially subversive political issues (cited in Critical Art Ensemble 2001: 5).

The pre-history of the term involves the 'tactical television' emphasis of the first N5M in Amsterdam in 1993, which brought together western artists, intellectuals and activists with their counterparts from the former communist countries of Eastern Europe (Critical Art Ensemble 2001, Lovink 2002, Rushkoff 1994). The emphasis on TV and the camcorder was broadened for the subsequent N5M in 1996 (Lovink 2002: 255; CAE 2001: 4).

Tactical media, writes Internet critic and activist Geert Lovink, one of the concept's key theorists, is 'a deliberately slippery term, a tool for creating 'temporary consensus zones' based on unexpected alliances. A temporary alliance of hackers, artists, critics, journalists and activists' (Lovink 2002: 271). ${ }^{3}$ Tactical media use is characterised by flexibility and mobility (some situations might be best tackled by making a website, others by making a phone call), by novelty and reinvention, and by a certain transient and temporary dimension 'hit and run, draw and withdraw, code and delete', as Lovink and Schneider put it (2001). It emphasises the technological, the transitory and the collaborative - qualities exemplified in the 'Revolution: USA' project, which is introduced in the following section. 


\section{Revolution: USA}

'Revolution: USA' was a 2004 tactical media project coordinated by UK electronic music act Coldcut and Canadian art duo NomIg. In 2001, Coldcut had released a track called 'Re:volution', which used as its hook a sample of UK Prime Minister Tony Blair announcing that 'the lunatics have taken over the asylum'. Coldcut themselves created the accompanying video clip using the VJAMM video-mixing software $<$ http: / / www.vjamm.com> which they had developed with multimedia firm Camart<http: / / www.camart.co.uk>, compiling a collage of political samples and newspaper headlines ridiculing both major UK political parties in the lead-up to the 2001 general election.

'Revolution: USA' extended this premise into an open access participatory project. For the 2004 US Presidential election, Coldcut and NomIg created the 'Revolution: USA' website to encourage others to remix Coldcut's original track with new US content $<$ http: / / www.revusa.net/main.php $>$. The site offered an enormous collection of samples, both audio and audio-visual, for use in remixes (fig. 1). A 300mb library of audio samples of the original 'Re:volution' recording was available, including extended and a capella mixes and samples of each individual instrumental track.

The 'about' page of the Revolution website states the project's aims as:

...to incite the public to assemble their own protest-ant [sic] magic from Coldcut's vast multimedia archive, including content uploaded by public contributors. The site also contains free audio 
loops and tracks created by Coldcut, which are available for use in would-be artist mixes. The aim is to build a digital A/V library replete with work that unearths the veiled wasteland of US politics, in order to invoke social change, and to create a new forum for meaningful artistic interactivity. $<$ http:/ / www.revusa.net/ subnavs.php?act=a>

The main page of the site featured a timeline of major US political events, scandals and international interventions dating back to 1960. Rolling the mouse over an item on the timeline would call up a brief descriptive text, accompanied by external links for further background reading and a selection of audio-visual samples, for the most part consisting of snatches of speeches or media appearances by political figures involved in the events in question. For example, Arnold Schwarzenegger's successful 2003 campaign to become Governor of California is represented on the timeline by a 50-word text, links to coverage archived at Fox News and CNN's websites, and two brief Quicktime movies of Schwarzenegger describing Democratic Party candidates as 'girlie men', which could be downloaded for remixing and recontextualisation. Unsurprisingly, the more recent events on the timeline generally had more accompanying video clips, while earlier events often had none, although users were able to upload clips of their own to expand the database: so, for example, there were more than twenty video clips of Bush, Colin Powell and others proclaiming the existence of Iraqi WMDs, but no samples to accompany the entry on the Bay of Pigs.

'Revolution: USA' was launched on 11 September 2004. When the project closed on election day, 2 November 2004, 36 user-submitted remixes were available from the front page. Some emphasised military and civilian deaths in Iraq; others drew contrasts between spending on 
defence and spending on foreign aid. Some concentrated on reworking footage of the Bush/Kerry presidential debates; others traced connections between the elder and younger Bush's Iraq interventions. Some were banal and unimaginative; others were downright inspired, such as Outerbongolia's collage of moments of Bush lost for words at press conferences over the Pixies' Surfer Rosa cut 'Where Is My Mind?', or the footage of the VJAMM Allstars' 15-minute live audio-visual mixing session, which climaxes with the main riff from Nirvana's 'Smells Like Teen Spirit' mixed in with samples of dancing troops and Darth Vader's light-sabre battle with Obi-Wan Kenobi. A featured piece was 'World of Evil' by TV Sheriff, which subsequently aired on MTV. 'World of Evil' drew on the full repertoire made available on the site, such as video samples of Richard Nixon ('the office of president will always be suspect') and Ronald Reagan ('government is the problem'). It also cut up samples to produce, for example, Madeleine Albright promising that 'As President, John Kerry will lead Nazi storm troopers to defeat and destroy the world'.

The entry selected as 'the winner' by Coldcut and NomIg was a Flash project by a design group called Future 3 $<$ http: / / www.future3.net/bush $>$. The interface combined a selection of computer keys, a cartoon image of five musicians and a screen area on which video loops played (fig. 2). Clicking on each of the musicians triggered a loop of guitar, bass, keyboards, drums or vocals, as well as triggering video samples showing images of death and destruction in Iraq. Clicking on one of the keys shown below triggered video loops of Bush, saying: freedom is beautiful, beautiful, people love freedom, freedom, we're corporate criminals, criminals, you're free, free, special evil, evil, money. The user can mix these either with a mouse or by typing, to produce new combinations of Bush declaring, for example, freedom is money, 
money is evil, or people love criminals freedom, and so on, layered over the other available combinations of the music loops.

\section{Revolution: USA as Tactical Media}

The 'Revolution: USA' project illustrates all the major characteristics of tactical media. First, it exploits the potential of new communications technologies. Second, it is built around remixing and reworking found material. Third, the project is satirical, and while not every tactical media project could be described as satirical, it is almost always an element. Fourth, 'Revolution: USA' works on the tactical principles of mobility, reinvention, temporariness and novelty. The project is ephemeral, a moment in a participatory activist culture: its traces remain as a web archive, but its energy and participants have since moved elsewhere. This section addresses these four points in turn.

First, 'Revolution: USA' illustrates how tactical media are inseparable from new media technologies. Tactical media practice involves, in Lovink's words, '... taking full advantage of the free spaces in the media that are continually appearing because of the pace of technological change and regulatory uncertainty' (2002: 265). The precursor concept of 'tactical television' revolved around the possibilities of camcorders and of new distribution possibilities such as cable and video. The discourse of tactical media subsequently emerged at the same time as the Net was establishing itself in the popular imagination.

'Revolution: USA' was entirely a product of the convergent media environment. It depended upon the convergence of computers, media content and telecommunications at all stages of its production, distribution and reception. It was built around the possibilities of 
sampling (the audio files provided to remix the 'Re:volution' track; the video archive of political speeches and sound bites), of remixing, and of the web as a distribution platform for dissonant perspectives. One distinguishing characteristic of tactical media practice is such use of new communications technologies to circumvent the established media, to create new channels for the circulation of images, arguments, and stories, each of which has in turn been created and manipulated by other new media technologies.

For example, Wax Audio's Bush-sings-'Imagine' recording made use of a karaoke version of the Lennon song, while its Bush samples came from the George W. Bush Public Domain Audio Archive. The resulting 'Imagine This' text is distributed free as part of a downloadonly mini-album from the Wax Audio website, but has been featured on radio stations around the world - a tactical media strike. The ways in which 'Imagine This' or any of the remixes generated through 'Revolution: USA' were created are of more significance here than the content of the recordings themselves; what count are the possibilities that were used in the production - the taking advantage of moments of creative opportunity afforded by technological adoption and adaptation.

Second, 'Revolution: USA' invited participants to remix existing texts, to subvert found material. It was not a song writing contest, but one which asked people to rework an existing Coldcut track. It did not ask people to write or shoot film, but to remix and re-purpose existing video samples. It was a project built around tactical principles of remixing, collage, Situationist detournement. ${ }^{4}$ Detournement can be thought of as 'a politics of subversive quotation, of cutting the vocal cords of every empowered speaker' (Marcus 1989: 179). It describes the sampling of texts or images from one context and their embedding in a 
new one; the creation of a synthesis that calls attention to both the original context and the new result. It is the 'reversal of perspective', in Situationist Raoul Vaneigem's terms: '...to stop seeing things through the eyes of the community, of ideology, of the family, of other people. To grasp hold of oneself as of something solid, to take oneself as starting point and centre' (Vaneigem 1983 [1967]: 144). Detournement is the reshaping of familiar signs into question marks.

The Situationists were a small band of writers, activists and artists whose membership churned constantly around the pivotal figure of Guy Debord. Active from the mid-1950s until the early 1970s, they sought to undermine what Debord called the spectacle: the integrated, commercialised cultural space in which 'Everything that was directly lived has moved away into a representation' (1987 [1967]: section 1). The society of the spectacle, Debord wrote, drew together five phenomena: 'incessant technological renewal; integration of state and economy; generalised secrecy; unanswerable lies; an eternal present' (1988: 11-12). Against this matrix of forces, the Situationists argued for art as revolutionary, and revolution as artistic — 'the possibility of a life of playful opportunity in which the satisfaction of desires, the realisation of pleasures, and the creation of chosen situations would be the principal activities' (Plant 1992: 2). Debord best illustrated the Situationist synthesis of art and activism in his account of how a band of Venezuelan student revolutionaries stole some paintings from an exhibition of old masters and attempted to exchange these for the release of political prisoners. The paintings were retrieved in a shoot-out, only for the students to hurl bombs at the police van taking the art works away: 'This is clearly an exemplary way to treat the art of the past,' wrote Debord, 'to bring it back into play for what really matters in life' (2002 [1963]: 161). 
The Situationists had their precursors too - the creative destructions of Dada (Richter 1965), the deliberate derangements of Surrealism (Alexandrian 1970). But while the practice of detournement could be traced back beyond the Situationists themselves, it is from their promotion of the concept that its contemporary influence largely flows. The influence of the Situationists often surfaces in projects which fall within the tactical media orbit. It is, for example, very clear in the work of Adbusters, for whom Debord in particular functions as something of a patron saint. Another example would be DJ Spooky's touring video project Rebirth Of A Nation, in which he remixes Griffith's film The Birth of a Nation - a film which, on the one hand, maintains its status as one of the foundational works of cinema while, on the other hand, it operated as a Ku Klux Klan recruiting film until the 1960s, if not beyond (Miller 2004: 84). DJ Spooky's project of detourning Griffith's film to subvert its racist dimension was explicitly proposed by the Situationists, who used the example of The Birth of a Nation to explain detournement in 1956 (Debord \& Wolman 1981 [1956]).

To detourn is to remix and, as Manovich (2006) argues, the remix aesthetic has become the fundamental logic of all cultural production. Cultural commentators as diverse as Richard Florida (2002) and DJ Spooky (aka Miller 2004) emphasise creativity as a matter of remixing, reworking, restating, recombining. As Miller puts it: 'play and irreverence toward the found objects that we use as consumers and a sense that something new was right in front of our oh-so-jaded eyes' (2004: 45). ${ }^{5}$

Third, 'Revolution: USA' was satirical. Satire is an underemphasised element of media activism, and is central to tactical media in particular. ${ }^{6}$ While not every tactical media project could be best described as satirical, satire is almost always an element. Satire is art on 
the attack: it aims to ridicule and provoke. 'The most potent weapons known to mankind,' as community organiser and tactical theorist Saul Alinsky wrote, 'are satire and ridicule' (1971: 75). Satire is inherently subversive. ${ }^{7}$ Like other forms of activism, satire asks questions about power and influence. Satirists and activists each make judgments about social, cultural and political standards and failings. Both satire and activism are, among other things, forms of cultural criticism. Satire and activism are both means of resistance to various forms of power, including symbolic power - and both attempt to draw attention to things which are often otherwise ignored, underplayed or taken for granted.

Of those projects most frequently discussed as tactical media ${ }^{\circledR}{ }^{\mathrm{TM}}$ ark's various impersonations, including as the Yes Men; the Electronic Disturbance Theater's virtual sit-ins; the 'Twelve Days of Christmas' campaign against online retailer etoys.com - each uses satire as part of its approach. Even the deadly serious struggles by Belgrade independent radio station B92 to circumvent censorship by the Milosevic regime (Lovink 2003) involved satirical interventions: for example, banned repeatedly from broadcasting, B92 at one point banned themselves for a day, pretending to have been taken over and turned into a state propaganda outlet (on the B92 example see Collin 2001: 57; on each of these examples see Meikle 2002).

Fourth, 'Revolution: USA' emphasised tactical media qualities of temporariness, mobility, novelty and reinvention. Tactical media projects, as Critical Art Ensemble note, are usually ephemeral (2001: 9). They depend, suggests Lovink, on 'the art of getting access' and on 'disappearing at the right moment' (2002: 260). Such emphases are where the debt of tactical media theory to Michel de Certeau is most apparent, building on his distinction between strategies (the 
exploitation of space, the privileging of place over time) and tactics (the exploitation of moments of opportunity and possibility made possible as cracks appear in the evolution of strategic place). This distinction underpins the concept of tactical media, which revolves around de Certeau's characterisation of the tactic:

It operates in isolated actions, blow by blow. It takes advantage of 'opportunities' and depends on them, being without any base where it could stockpile its winnings, build up its own position, and plan raids. What it wins it cannot keep. This nowhere gives a tactic mobility, to be sure, but a mobility that must accept the chance offerings of the moment, and seize on the wing the possibilities that offer themselves at any given moment. It must vigilantly make use of the cracks that particular conjunctions open in the surveillance of the proprietary powers. It poaches in them. It creates surprises in them. It can be where it is least expected. It is a guileful ruse (de Certeau 1984: 37).

\section{But does it work?}

The emphasis on this conception of the tactical in so much media activism raises real questions. For example, as Wark (2002) asks, how can networks be built and sustained on practices which favour hit-andrun media gestures, temporary coalitions and disappearances? Conversely, does the very popularity of the term mean that tactical media risks becoming frozen as a particular set of gestures and actions — the detourned advertisement, the over-identified press release, the pie-struck politician — with the impulse towards reinvention being underplayed? Moreover, what do tactical media interventions really accomplish? George W. Bush, one need hardly point out, was re- 
elected in 2004. Should one conclude that Republican party activists were getting out the vote, while tactical media activists were at home remixing old Coldcut tunes? Or that tactical media and the wider activist participatory online culture displace energy that is needed for old-fashioned organising? This latter tension has long been felt and continues to be voiced (see e.g. Dean, this volume). The second part of Lovink and Garcia's tactical media manifesto, 'The DEF of Tactical Media', framed it as 'Simulation vs. Real Action':

For many, the urgency of some of the questions we are facing generate an angry scepticism around any practice that raises art or media questions. For real actionists the equation is simple, discourse $=$ spectacle. They insist on a distinction between real action and the merely symbolic. From this perspective media tacticians are accused of merely talking not doing anything. By focusing on the media question we are accused of just creating more empty signs (Garcia \& Lovink 1999).

Social movement scholars might explore this tension as one between 'instrumental' and 'expressive' activism: 'the activities of social movements are in part expressive; in part instrumental; in part directed at their own members; in part designed to transform the external environment' (Della Porta \& Diani 2006: 196). On the instrumental side, activists have tangible goals, changes they wish to effect, laws they wish to change, outcomes they hope to achieve. On the expressive side, communicating these objectives to the wider public often demands media gestures, stunts, gimmicks. What's more, as Della Porta and Diani note, such gestures can be directed at participants as much as (or even more than) this wider public. Stacked up against the problems of the day, the expressive activism of cultural activities such as remixing video clips of George Bush can seem hopelessly unreal, misguided, 
ineffective or pointless. However, such activity of course has its own goals and objectives, its own value. For example, as Maddison and Scalmer point out, expressive activism can communicate an idea to the wider public, it can draw attention to issues and raise questions, it can create a space in public debate for activist perspectives, it can challenge complacency (2006: 72). The next section pursues this direction in further detail.

\section{Tactical Media as Play}

An instrumental activist assessment of tactical media, then, would ask, in essence, does it work? This chapter proposes instead that a more interesting question is does it play? To ask of the 'Revolution: USA' project, does it work? would be to tap into such questions as 'Has it raised public awareness and support? Has it affected government policy? Is there a tangible political outcome?' However, to ask instead, does it play? would be to tap into quite different sorts of question questions which point towards the creators or participants and towards the users of the project, rather than towards the policymakers, governments and corporations which are the usual targets of contemporary activist interventions. Tactical media provokes creative engagement with media texts and media technologies, and it does so in the context of a burgeoning participatory culture. In this context, then, it is possible to move beyond the does it work? question and instead ask questions of creativity and engagement.

To ask does it play? would be to open up such questions as: Is it creative? This is an interesting question in relation to activism: after all, as Richard Florida points out, creativity is inherently subversive, as it disrupts existing patterns of living and thinking (2002: 31). Does it encourage the user, the audience, to be creative? What would count here, as 
Walter Benjamin said in the 1930s, would be the transformation effected on the audience: '...readers and spectators into collaborators' (Benjamin 1978: 233). Does it use humour? 'A good tactic', Saul Alinsky suggested, 'is one that your people enjoy. If your people are not having a ball doing it, there is something very wrong with the tactic' (1971: 128).

An important resource for thinking about such questions of play is Brian Sutton-Smith's book The Ambiguity of Play (1997). ${ }^{8}$ Sutton-Smith explores the range of ways in which play is understood and expressed, and identifies seven different rhetorics - or discourses - of play. First, the discourse of play as progress, through which ideas of play as central to learning and development are expressed. Second, play as fate, the discourse of play as gambling, luck and chance, the belief in a controlling destiny. Third, play as power, the rhetoric of contests and sport: 'the use of play as the representation of conflict' (1997: 10). Fourth, play as identity: in Sutton-Smith's analysis, this discourse is 'usually applied to traditional and community celebrations and festivals [...] when the play tradition is seen as a means of confirming, maintaining, or advancing the power and identity of the community of players' (1997: 10). Fifth, play as the imaginary - the language of play as it relates to creativity, to innovation, to imagination and improvisation. Sixth, play and the self, a discourse of personal experience and satisfaction, of self-fulfilment and relaxation. Finally, play as frivolous: the discourse that can be set against the work ethic (cf. Kane 2004), and applied to 'historical trickster figures and fools, who were once the central and carnivalesque persons who enacted playful protest against the orders of the ordained world' (Sutton-Smith 1997: 11).

Each of these discourses of play (with the possible exception of play as fate) opens up possibilities for considering tactical media. Each 
would suggest different questions which could be asked of a project such as 'Revolution: USA', questions that move past the instrumental does it work? For example, situating tactical media within the discourse of play as progress would make it possible to ask what opportunities are presented for learning and development - as activists, as citizens, as people involved in mediated communication, as individuals, as members of a group or community. To situate tactical media within the discourse of play as imagination would offer different perspectives, suggesting such questions as: to what extent does the project offer resources for participants to improvise with and/or to improve? Does it draw upon the imaginative resources of its users? Does it encourage its users to use their imaginations? And to situate tactical media within the discourse of play as frivolity might open up such deceptively simple questions as: Is it enjoyable? Is it engaging? Is it something that people will enjoy doing, above and beyond whatever political merits the project may or may not have?

As an example, we might take further just one of Sutton-Smith's discourses of play, that of play as identity. This involves conceptualising play as a form of bonding, of community formation and maintenance and renewal, of play designed around 'potentially cooperative identity' (1997: 100). In this conception of play as expressed in festivals and celebrations, in the creation and sustaining of community, one might hear echoes of Bakhtin's account of medieval carnivals and their elision of the distinction between participant and spectator (1984: 7). Or one might see the outlines of more contemporary temporary autonomous zones (Bey 1991) such as Reclaim The Streets (Jordan 1998).

From this perspective of play as identity, what would it mean to ask of 'Revolution: USA', does it play? To ask this would be to draw 
attention to, among other things, the limited time-span of the project, an eight-week festival of participatory video, and an opportunity for pleasurable and/or satirical participation in the final phase of the election campaign. It would also be to draw attention to the project not as an instrumental website for the provision of information, for the cause-and-effect delivery of messages and recruitment of voters, but rather as a space for the creation and maintenance of a community, a point-of-view, a shared context — ritual communication, in Carey's terms (1989). From this perspective, 'Revolution: USA' is significant not for its capacity to influence policy, but for the resources it offers users to collaborate, to create their own media, to participate in the debates, and to act as citizens as well as audiences - with citizenship defined at least in part here in terms of symbolic power, of participation in mediated conversations. Most of all, it is significant in its creation of a space for participants to come together and recognise in each other at least a fleeting commonality.

\section{Conclusion}

This chapter began by discussing tactical media as manifestations of symbolic power, something which cannot help but sound serious even grave - and it ended by proposing tactical media as forms of play. This is not bathos - because play is a deadly serious business. The chapter has also referred to satire more than once, and so is subject to the statutory requirement to invoke Jonathan Swift: it is, then, a modest proposal - that the discourses and practices of tactical media, as manifestations of symbolic power, might best be approached by asking not does this work? but rather does this play? 


\section{References}

Alexandrian, S. 1970. Surrealist Art. London: Thames and Hudson.

Alinsky, S. D. 1971. Rules For Radicals. New York: Vintage Books.

Bakhtin, M. 1984. Rabelais and His World. Bloomington: Indiana University Press.

Benjamin, W. 1978 [1934]. 'The Author as Producer'. In Reflections, pp. 220-38. New York: Harcourt Brace Jovanovich.

Bey, H. 1991. T.A.Z.: the Temporary Autonomous Zone, Ontological Anarchy, Poetic Terrorism. New York: Autonomedia.

Bourdieu, P. 1991. Language and Symbolic Power. Cambridge: Polity Press.

Carey, J. 1989. Communication as Culture. New York: Routledge.

Collin, M. 2001. This Is Serbia Calling: Rock'n'Roll Radio and Belgrade's Underground Resistance. London: Serpent's Tail.

Critical Art Ensemble. 2001. Digital Resistance: Explorations in Tactical Media. New York: Autonomedia.

de Certeau, M. 1984. The Practice of Everyday Life. Berkeley: University of California Press.

Debord, G. 1987 [1967]. The Society of the Spectacle. Exeter: Rebel Press. 
1988. Comments on the Society of the Spectacle. London: Verso.

2002 [1963]. "The Situationists and the New Forms of Action in Politics or Art'. In Tom McDonough, ed., Guy Debord and the Situationist International: Texts and Documents, pp. 159-66. Cambridge, MA: MIT Press.

and G. Wolman. 1981 [1956]. 'Methods of Detournement'. In Ken Knabb, ed., Situationist International Anthology, pp. 8-14. Berkeley: Bureau of Public Secrets.

Della Porta, D. and M. Diani. 2006. Social Movements (second edition). Malden, MA: Blackwell.

Florida, R. 2002. The Rise of the Creative Class. New York: Basic Books.

Garcia, D. and G. Lovink. 1997. 'The ABC of Tactical Media'. Posted to the $<$ nettime $>$ list on 16 May, archived at $<$ http: / / www.nettime.org/Lists-Archives / nettime-19705/msg00096.html>, accessed 21 December 2006.

1999. 'The DEF of Tactical Media'. Posted to the $<$ nettime $>$ list on 22 February, archived at <http: / / www.nettime.org/ ListsArchives / nettime-1-9902/ msg00104.html>, accessed 21 December 2006.

Huizinga J. 1950. Homo Ludens: A Study of the Play-Element in Culture. Boston: Beacon Press.

Jordan, J. 1998. 'The Art of Necessity: the Subversive Imagination of Anti-Road Protest and Reclaim the Streets'. In George McKay, ed., DiY Culture: Party $\mathcal{E}$ Protest in Nineties Britain, pp. 129-51. London: Verso. 
Kane, P. 2004. The Play Ethic. London: Macmillan.

Lewis, P. 2006. Cracking Up: American Humor in a Time of Conflict.

Chicago: University of Chicago Press.

Lovink, G. 2002. Dark Fiber: Tracking Critical Internet Culture.

Cambridge, MA: MIT Press.

2003. My First Recession: Critical Internet Culture in Transition. Rotterdam: V2_Publishing/Nai Publishers.

and F. Schneider. 2001. 'New Rules of the New Actonomy'.

Posted to the $<$ nettime list $>$ on 25 June, archived at

$<$ http: / / amsterdam.nettime.org/Lists-Archives / nettime-1-

0106/msg00114.html>, accessed 23 February 2004.

Maddison, S. and S. Scalmer. 2006. Activist Wisdom: Practical Knowledge and Creative Tension in Social Movements. Sydney: UNSW Press.

Manovich, L. 2006. 'Generation Flash'. In Wendy Hui Kyong Chun and Thomas Keenan, eds, New Media Old Media: A History and Theory Reader, pp. 209-218. New York, Routledge.

Marcus, G. 1989. Lipstick Traces: a Secret History of the Twentieth Century. London: Picador.

Meikle, G. 2002. Future Active: Media Activism and the Internet. New York: Routledge. 
Miller, P. D. aka DJ Spooky That Subliminal Kid. 2004. Rhythm Science. Cambridge, MA: MIT Press.

Plant, S. 1992. The Most Radical Gesture: the Situationist International in a Postmodern Age. London: Routledge.

Richter, H. 1965. Dada: Art and Anti-Art. London: Thames and Hudson.

Rushkoff, D. 1994. Media Virus! Sydney: Random House.

Scott, J. C. 1985. Weapons of the Weak: Everyday Forms of Peasant Resistance. New Haven: Yale University Press.

Sutton-Smith, B. 1997. The Ambiguity of Play. Cambridge, MA: Harvard University Press.

Thompson, J. B. 1995. The Media and Modernity. Cambridge: Polity Press.

Vaneigem, R. 1983 [1967]. The Revolution of Everyday Life. London: Rebel Press and Left Bank Books.

Wark, M. 2002. 'Strategies For Tactical Media'. Realtime, October, <http: / / www.realtimearts.net/rt51/ wark.html>, accessed 21 December 2006.

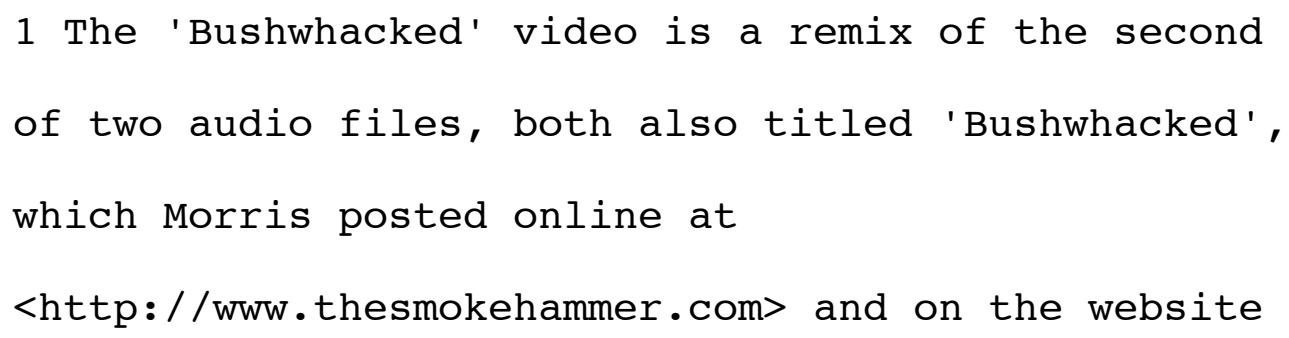


of Warp records. The video is also included as an extra on the DVD release of Morris's 1994 BBC TV series The Day Today, a six-part surrealist news satire.

2 Also important here was the 'Bush in 30 Seconds' contest sponsored by Moveon.org: this contest invited advocacy, parody and outsider TV commercials to feed into the 2004 presidential election campaign <http://www.bushin30seconds.org>. More than a thousand ads were submitted, although many of these were not remix-based, and so are beyond the focus of this chapter. The winning entry - 'Child's Pay' by Charlie Fisher - was rejected for broadcast by CBS, although it of course spread across the Net. Many of these ads, including 'Child's Pay' can also still be viewed online at <http://www.archive.org> among other places.

3 There is a certain unresolved quality to the definition of tactical media which is itself part of the discourse (and part of its power). See for example the catalogue of definitions maintained online as part of NYU's Virtual Casebook project 
<http://www.nyu.edu/fas/projects/vcb/definingTM.html $>$, accessed 21 December 2006 .

4 This term is not generally translated from the French, but rather anglicised. Plant suggests that the best English equivalent would fall 'somewhere between "diversion" and "subversion"' (1992: 86). 5 Miller contributed to an interesting online discussion of remix culture on the listserv of the Institute for Distributed Creativity in April 2006, archived at <http://mailman.thing.net/pipermail/idc>. 6 One could go further, as Paul Lewis does in Cracking Up, arguing that satire and humour are central to contemporary political discourse, at least in the US, which is the site of his study. 7 The fact that satire is inherently subversive made it all the more striking when, in February 2007, Rupert Murdoch's Fox News aired pilots of a 'conservative satire' show intended as a deliberate counter to Jon Stewart's The Daily Show. One trailer for the Fox Show (The Half Hour News Hour) featured right-wing broadcaster Rush Limbaugh as US President in 2009, with conservative columnist Ann Coulter as 
Vice-President. 'Stay tuned', said Limbaugh to the viewer. 'And if you don't,' added Coulter over a laugh-track, 'we'll invade your countries, kill your leaders, and convert you to Christianity'. But was this satire? Or a restatement of actual foreign policy positions? After all, Coulter's line came from her own column of 13 september 2001. However, the fact that Fox perceived a need for such a show with a right-wing slant underscores the political significance and potential influence of satire. 8 I was led to The Ambiguity of Play by Pat Kane's book The Play Ethic, which also uses Sutton-Smith's analysis. Kane, however, makes much larger claims than does the present chapter, seeing in concepts of play an entire ideology, the values of which include: '.. play as a source of human energy; as a perpetual engagement with the world; as a mentality capable of living with uncertainty and risk; as an attractive form of collective identity; as an imaginative, symbolic freedom; as a spirit of honesty and integrity; as a saving sense of humour and subversion' (2004: 257). Other important attempts to take play as seriously as it deserves 
include: Huizinga's Homo Ludens (1950); Richard Neville (1970) Play Power, London: Jonathan Cape; McKenzie Wark (2007) GAMER THEORY, Cambridge, Massachusetts: Harvard University Press. 